\title{
Urgensi Kualitas Pelayanan Distribusi Zakat Produktif Terhadap Kepuasan Mustahiq
}

\author{
Sukma Mehilda*, Meliyana, Decky Hendarsyah \\ Sekolah Tinggi Ilmu Ekonomi (STIE) Syariah Bengkalis Riau, Indonesia \\ sukma.mehilda@gmail.com
}

\section{Copyright (C) 2021 The Author}

This is an open access article

Under the Creative Commons Attribution-ShareAlike 4. 0 International License

\begin{abstract}
Productive zakat is something that can support productivity for the economy and mustahiq life. Mustahiq satisfaction in getting productive zakat is a reflection of the success of the service. This study aims to analyze the effect of the quality of productive zakat distribution services on mustahiq satisfaction at the national zakat agency (NZA) Bengkalis district. This study was built using a quantitative descriptive method based on primary and secondary data in questionnaires, documentation, and literature studies. The total population of productive zakat mustahiqat the NZA Bengkalis regency is 327 people. Sampling used random sampling with a total sample of 77 people. Data were analyzed using simple linear regression, previously tested using validity, reliability, and normality tests. This study indicates that the quality of productive zakat distribution services has urgency in creating satisfaction for mustahiq, with evidence that the quality of productive zakat distribution services has a positive and significant effect on mustahiq satisfaction. This study contributes to NZA Bengkalis regency in improving service quality and satisfaction of productive zakat mustahiq.
\end{abstract}

Keywords: servuce quality; satisfaction; distribution; productive zakat; mustahiq

\begin{abstract}
ABSTRAK
Zakat produktif merupakan suatu hal yang dapat menunjang produktifitas bagi perekonomian dan kehidupan mustahiq. Kepuasan mustahiq dalam mendapatkan zakat produktif merupakan cerminan keberhasilan dari pelayanan.Kajian ini bertujuan untuk menganalisis pengaruh kualitas pelayanan distribusi zakat produktif terhadap kepuasan mustahiq pada badan amil zakat nasional (BAZNAS) kabupaten Bengkalis.Kajian ini dibangun menggunakan metode deskriptif kuantitatif yang bersumberkan pada data primer dan sekunder berupa kuesioner, dokumentasi dan studi pustaka. Jumlah populasi mustahiq zakat produktif pada BAZNAS kabupaten Bengkalis sebanyak 327 orang. Pengambilan sampel menggunakan random sampling dengan jumlah sampel sebanyak 77 orang.Data dianalisis menggunakan regresi linear sederhana, sebelumnya diuji menggunakan uji validitas, reliabilitas dan normalitas. Hasil kajian ini menunjukkan bahwa kualitas pelayanan distribusi zakat produktif memiliki urgensi dalam menciptakan kepuasan kepada mustahiq, dengan bukti kualitas pelayanan distribusi zakat produktif berpengaruh positif dan signifikan terhadap kepuasan mustahiq.Kajian ini memberikan kontribusi kepada BAZNAS kabupaten Bengkalis dalam meningkatkan kualitas pelayanan dan kepuasan mustahiq zakat produktif.
\end{abstract}

Kata Kunci: kualitas pelayanan; kepuasan; distribusi; zakat produktif; mustahiq 


\section{A. PENDAHULUAN}

Kurun waktu lima tahun terakhir kajian mengenai kepuasan sudah menjadi hal yang menarik bagi para peneliti di dunia. Secara umum kepuasan sudah dikaji dari beberapa sektor seperti perbankan, pendidikan, pariwisata dan sebagainya. Walaupun kepuasan sudah dikaji dari berbagai sektor, namun permasalahan kepuasan di belahan dunia masih tetap menjadi telaah di berbagai negara, seperti kepuasan hidup imigran di Eropa (Heizmann \& Böhnke, 2019), meningkatkan kepuasan kerja guru di Amerika Serikat (Edinger \& Edinger, 2018), kepuasan hidup di India, China dan Jepang (Tsurumi \& Managi, 2020), kepuasan pelanggan kopi Starbuck di India (Pandey et al., 2021), dan kepuasan nasabah bank di Sulawesi Tenggara Indonesia (Nasrul, 2021).

Solusi mengenai kepuasan yang sudah ada selama ini secara umum yaitu mengenai pelayanan. Namun pelayanan yang biasa saja tidak cukup untuk memuaskan konsumen di berbagai sektor. Sebab Indonesia sebagai negara yang kaya akan ragam budaya, adat ketimuran dan religiusitas serta mayoritas beragama Islam, mengajarkan kepada insan yang ada bahwa kebaikan akan memberikan nilai yang positif. Apalagi kebaikan tersebut memberikan kepuasan kepada komunitas sosial keagamaan, maka akan mendapat ganjaran yang baik dari sang pencipta. Oleh sebab itu pelayanan yang diberikan haruslah berkualitas baik.

Sejauh ini kajian mengenai kualitas pelayanan terhadap kepuasan sudah banyak dilakukan dengan metode dan hasil yang beragam. Kajian kualitas pelayanan terhadap kepuasan dapat dilihat dari beberapa sektor. Pertama, di sektor perbankan kajian dilakukan oleh (Alamgir Hossain, Yesmin, Jahan, \& Kim, 2021; Aslam, Tariq, \& Arif, 2019; Fauzi \& Suryani, 2019; Islam, Ahmed, Rahman, \& Asheq, 2020; Rahaman, Ali, Kejing, Taru, \& Mamoon, 2020; Wiyanto, 2016). Kedua, di sektor teknologi kajian dilakukan oleh (Pawirosumarto, 2016; Setiawan, 2016). Ketiga, di sektor perdagangan kajian dilakukan oleh (Balinado et al., 2021; Kang, 2020). Keempat, di sektor pariwisata kajian dilakukan oleh (Alvianna, 2017; Kumar, Govindarajo, \& Khen, 2020; Nunkoo, Teeroovengadum, Ringle, \& Sunnassee, 2020). Kelima, di sektor keuangan kajian dilakukan oleh (Farida, 2017). Keenam, di sektor industri kajian dilakukan oleh (Dewi, Hajadi, Handranata, \& Herlina, 2021). Ketujuh, di sektor pendidikan kajian dilakukan oleh (Afthanorhan, Foziah, Rusli, \& Khalid, 2019; Alam, 2021). Kedelapan, di sektor kesehatan kajian dilakukan oleh (Akbar, Ulfah, \& Maretta, 2020; Ernawaty, Supriyanto, Krisbianto, \& Visianti, 2020; Ndayisenga \& Tomoliyus, 2019; Pradeep, Vadakepat, \& Rajasenan, 2020). Kesembilan, di sektor transportasi kajian dilakukan oleh (Farooq, Salam, Fayolle, Jaafar, \& Ayupp, 2018; Yudhistira, 2019). Namun dari kajian tersebut belum ditemukan kajian yang melakukan pembahasan di sektor sosial keagamaan tepatnya pada pengelolaan zakat produktif.

Setiap sektor memiliki konteks dan karakter yang berbeda dalam memberikan pelayanan sehingga berdampak terhadap kepuasan konsumen pada masing-masing sektor. Oleh sebab itu, kajian ini bertujuan untuk menganalisis pengaruh kualitas pelayanan distribusi zakat produktif terhadap kepuasan mustahiq pada Badan Amil Zakat Nasional (BAZNAS) Kabupaten Bengkalis. Kajian ini ingin menunjukan bukti baru dengan cara melakukan pengujian pada sektor yang berbeda yaitu sektor sosial keagamaan menggunakan indikator dan alat pengujian 
yang berbeda. Hasil kajian ini akan memberikan kontribusi kepada BAZNAS Kabupaten Bengkalis dalam meningkatkan kualitas pelayanan dan kepuasan mustahiq zakat produktif.

\section{B. KAJIAN PUSTAKA}

Zakat merupakan salah satu rukun Islam yang wajib ditunaikan bagi umat Islam yang mampu atau memiliki harta (Hendarsyah, 2013). Zakat adalah hak yang wajib dikeluarkan dari harta jika sudah memenuhi syarat yang telah ditetapkan bagi umat Islam (Atabik, 2015). Zakat didasarkan kepada kebutuhan untuk memberi bantuan sosial dan kesejahteraan umum demi kepentingan dan kemajuan umat Islam (Owoyemi, 2020). Zakat dinilai dari dua dimensi yaitu ketaatan kepada Allah SWT (dimensi vertikal) dan kewajiban terhadap sesama manusia (dimensi horizontal) (Saputra, 2020). Sehingga zakat menjadi wujud nyata dari ibadah seorang muslim kepada Allah sekaligus wujud kepedulian sosial (Ishak, 2012). Kewajiban zakat merupakan perintah Allah yang terdapat dalam surat At-Taubah ayat 103:

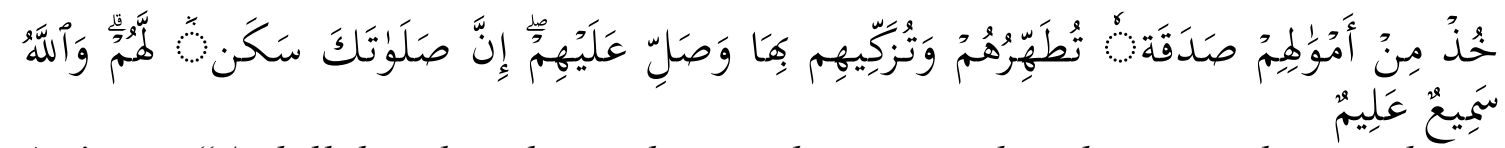

Artinya: "Ambillah zakat dari sebagian harta mereka, dengan zakat itu kamu membersihkan dan mensucikan mereka dan mendoalah untuk mereka. Sesungguhnya doa kamu itu (menjadi) ketenteraman jiwa bagi mereka. Dan Allah Maha Mendengar lagi Maha Mengetahui” (Mushaf, 2021).

Zakat dilihat dari segi pendistribusiannya terbagi atas dua, yaitu zakat konsumtif dan zakat produktif. Zakat konsumtif merupakan zakat yang didistribusikan langsung kepada mustahiq yang digunakan untuk memenuhi kebutuhan hidupnya (Safradji, 2018). Sedangkan zakat produktif merupakan zakat yang didistribusikan langsung kepada mustahiq yang digunakan untuk membuka usaha baru atau mengembangkan usaha yang telah ada, sehingga dengan usaha tersebut dapat memenuhi kebutuhan hidupnya secara kontinue dan diharapkan di masa yang akan datang juga berzakat (Anwar, 2018).

Kualitas pelayanan merupakan tingkat perbedaan antara harapan dan presepsi serta penilaian atau sikap konsumen secara elaboratif terhadap kinerja layanan yang sedang dirasakan (Islam et al., 2020; Kang, 2020). Kualitas pelayanan merupakan faktor penting bagi organisasi atau perusahaan dalam meningkatkan daya saing, perkembangan dan pertumbuhan bisnis (Rahaman et al., 2020). Kemudian kualitas pelayanan juga merupakan faktor penting dalam menafsirkan kepuasan (Balinado et al., 2021)

Dimensi kualitas pelayanan terdiri dari (Alam, 2021; Balinado et al., 2021; Fauzi \& Suryani, 2019): (a) Reliability (kehandalan), kemampuan untuk memberikan pelayanan yang sesuai dengan tawaran.(b) Assurance (jaminan), kemampuan dalammengetahui produk secara tepat, jaminan keselamatan, keterampilan dalam memberikan keamanandan kemampuan dalam menanamkan kepercayaan konsumen. (c)Tangibles (tampilan), wujud secara fisik yang meliputi penampilan dan kelengkapan fasilitas fisik perusahaan. (d) Empathy (empati), perhatian secara individu yang diberikan perusahaan terhadap konsumen. (e) Responsiveness (ketanggapan dan 
kepedulian), respon atau kesigapan dalam membantu konsumen dan memberikan pelayanan yang cepat dan tanggap.

Kepuasan merupakan perilaku atau tindakan yang mewakili perasaan konsumen setelah menggunakan suatu layanan apakah sudah sesuai dengan harapan atau tidak (Islam et al., 2020). Kepuasan mengacu pada keadaan psikologis, dimana konsumen memiliki perasaan atau pengalaman sebelumnya (Kang, 2020). Kepuasan konsumen merupakan faktor penting dalam pertumbuhan dan eksistensi organisasi atau perusahaan (Kang, 2020). Dimensi kepuasan terdiri dari attitude (sikap), happiness (bahagia), dan satisfaction (puas) (Supriyanto, Wiyono, \& Burhanuddin, 2021). Mengukur kepuasan konsumen dapat dilakukan dengan cara mengevaluasi kepuasan secara menyeluruh, konfirmasi harapan, dan perbandingan kondisi ideal dari presepsi (Budiarti, 2011). Kepuasan konsumen akan menjadikan pengalaman positif bagi konsumen sehingga akan mengulangi kembali penggunaan layanan yang telah digunakan sebelumnya (Lubis, Dalimunthe, Absah, \& Fawzeea, 2021). Kepuasan dapat menjadi faktor penentu bagus atau tidak kualitas pelayanan seperti akses, komunikasi, kompetensi, kesopanan, kredibilitas, keandalan, daya tanggap, keamanan, pemahaman, dan bukti fisik (Xiao, Ren, Zhang, \& Ketlhoafetse, 2020).

Kajian empiris disektor perbankan menemukan bahwa kualitas pelayanan berpengaruh siginifikan terhadap kepuasan nasabah, dilakukan oleh (Budiarti, 2011; Hilal \& Djatola, 2018; Lubis et al., 2021; Mubarok, 2016; Mutmainnah, 2018; Supriyanto et al., 2021). Selanjutnya di sektor teknologi menemukan bahwa kualitas pelayanan berpengaruh signifikan terhadap kepuasan pengguna, dilakukan oleh (Pawirosumarto, 2016; Setiawan, 2016). Pada sektor perdagangan menemukan bahwa kualitas pelayanan berpengaruh signifikan terhadap kepuasan konsumen, dilakukan oleh (Biswas \& Roy, 2020; Hidayah, Tauwli, \& Saefudin, 2020; Kang, 2020; Maharsi, Njotoprajitno, Hadianto, \& Wiraatmaja, 2021; Shartykarini, Firdaus, \& Rusniati, 2016). Pada sektor pariwisata menemukan bahwa kualitas pelayanan berpengaruh signifikan terhadap kepuasan wisatawan, dilakukan oleh (Alvianna, 2017; Kumar et al., 2020). Pada sektor keuangan menemukan bahwa kualitas pelayanan berpengaruh signifikan terhadap kepuasan investor, dilakukan oleh (Farida, 2017). Pada sektor pendidikan menemukan bahwa kualitas pelayanan berpengaruh signifikan terhadap kepuasan konsumen, dilakukan oleh (Afthanorhan et al., 2019; Stephen, Abu, Loy, \& Belkhamza, 2019). Pada sektor kesehatan menemukan bahwa kualitas pelayanan berpengaruh signifikan terhadap kepuasan pelanggan, dilakukan oleh (Ndayisenga \& Tomoliyus, 2019; Xiao et al., 2020). Pada sektor industri menemukan bahwa kualitas pelayanan berpengaruh signifikan terhadap kepuasan konsumen, dilakukan oleh (Dewi et al., 2021). Selanjutnya sektor transportasi menemukan bahwa kualitas pelayanan berpengaruh signifikan terhadap kepuasan konsumen, dilakukan oleh (Roh \& Choi, 2019; Yudhistira, 2019). Namun hasil yang berbeda temukan dalam kajian (Al Idrus, Abdussakir, Djakfar, \& Al Idrus, 2021), yang menyatakan kualitas pelayanan berpengaruh negatif dan siginifikan terhadap kepuasan pelanggan. Kajian ini memprediksi bahwa kualitas pelayanan distribusi zakat produktif akan menjadi faktor penting dalam meningkatkan kepuasan mustahiq, sehingga dapat diajukan hipotesis sebagai berikut: 
$\mathrm{H}_{1}$ : kualitas pelayanan distribusi zakat produktif berpengaruh signifikan terhadap kepuasan mustahiq.

\section{METODE PENELITIAN}

Kajian ini dilaksanakan pada kantor Badan Amil Zakat Nasional (BAZNAS) Kabupaten Bengkalis. Populasi pada kajian ini adalah mustahiq penerima zakat produktif BAZNAS kabupaten Bengkalis sebanyak 327 orang. Teknik pengambilan sampel menggunakan random sampling, untuk mencari jumlah sampel menggunakan rumus Slovin, sehingga didapat jumlah sampel sebanyak 77 orang. Kajian ini dibangun menggunakan metode deskriptif kuantitatif yang bersumberkan pada data primer dan sekunder berupa kuesioner, dokumentasi dan studi pustaka. Setelah data terkumpul, maka dilakukan uji validitas, reliabilitas dan normalitas, kemudian dianalisis menggunakan regresi linear sederhana, uji hipotesis dan koefisien determinasi.

\section{HASIL DAN PEMBAHASAN}

\section{Distribusi Zakat Produktif}

Zakat produktif merupakan salah satu penunjang produktifitas bagi mustahiq. Pendistribusian zakat bermanfaat untuk menambah modal atau sebagai modal awal dari usaha mustahiq. Pelayanan distribusi dana zakat produktif yang dilakukan BAZNAS Kabupaten Bengkalis terdiri dari sosialisasi, pengumpulan data, pendistribusian, pendayagunaan dan pengawasan. Pendistribusian dana zakat produktif dilakukan dalam bentuk pemberian modal usaha kepada mustahiq secara langsung. Praktik pendistribusian zakat produktif BAZNAS kabupaten Bengkalis merujuk kepada Undang-Undang Nomor 23 Tahun 2011 tentang Pengelolaan Zakat.

\section{Data Responden}

Kuesioner disebar kepada 77 orang mustahiq BAZNAS Kabupaten Bengkalis dan semua mustahiq mengisi dan mengembalikan kuesioner. Setelah data kuesioner diolah, maka data mustahiq dapat di kategorikan berdasarkan jenis kelamin, tingkat pendidikan dan umur. Bedasarkan jenis kelamin didapat jumlah laki-laki sebanyak $45(58,4 \%)$ dan perempuan sebanyak $32(41,6 \%)$. Kemudian berdasarkan tingkat pendidikan didapat jumlah pendidikan tingkat SD sebanyak 39 (50,6\%), tingkat SMP sebanyak $17(22,1 \%)$ dan tingkat SMA sebanyak $21(27,3 \%)$. Selanjutnya berdasarkan umur didapat jumlah rentang umur 21-25 sebanyak 1 orang (1,29\%), rentang umur 26-30 tidak ada, rentang umur 31-35 sebanyak 3 orang $(3,89 \%)$, rentang umur $36-40$ sebanyak 31 orang $(40,26 \%)$ dan rentang umur 41 keatas sebanyak 42 orang $(54,56 \%)$.

\section{Validitas dan Reliabilitas}

Dalam menentukan validitas data perlu diketahui nilai $\alpha, \mathrm{n}$ dan df sehingga bisa didapat nilai $r_{\text {tabel. }}$.Kemudian data dikatakan valid jika nilai $r_{\text {hitung }}>r_{\text {tabel }}$. Berdasarkan data kuesioner diketahui nilai $\alpha=0,05 ; \mathrm{n}=77$; df $=\mathrm{n}-2=77-2=75$, sehingga dapat dilihat nilai $\mathrm{r}_{\text {tabel }}$ dengan menggunakan distribusi tabel $r$ dandidapat hasil $r_{\text {tabel }}$ yaitu sebesar 0,277. Berdasarkan olahan data primer, variabel kualitas pelayanan distribusi zakat produktif 
menunjukkan nilai $\mathrm{r}_{\text {hitung }}$ terendah sebesar 0,596 dan nilai $\mathrm{r}_{\text {hitung }}$ tertinggi sebesar 0,769 . Variabel kepuasan mustahiqmenunjukkan nilai $\mathbf{r}_{\text {hitung }}$ terendah sebesar 0,579 dan nilai $\mathbf{r}_{\text {hitung }}$

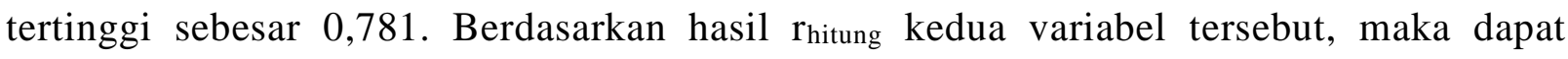
dinyatakan bahwa $\mathbf{r}_{\text {hitung }}>\mathbf{r}_{\text {tabel }}$, artinya data dalam keadaan valid.

Dalam menentukan reliabilitas data dilihat dari nilai cronbach's alpha jika besar dari 0,05 maka data dikatakan reliabel. Berdasarkan olahan data primer, variabel kualitas pelayanan distribusi zakat produktif menunjukkan nilai cronbach's alpha sebesar 0,920. Variabel kepuasan mustahiqmenunjukkan nilai cronbach's alpha sebesar 0,897. Berdasarkan hasil kedua variabel tersebut, maka nilai cronbach's alpha> 0,05, artinya data dapat dinyatakan reliabel.

\section{Normalitas}

Uji normalitas pada model regresi digunakan untuk menguji apakah nilai residual yang dihasilkan dari regresi terdistribusi secara normal atau tidak. Uji normalitas data dalam kajian ini menggunakan kolmogorov-smirnov dan grafik p-plot. Dalam menentukan normalitas data berdasarkan kolmogorov-smirnov dilihat dari nilai signifikansi yang dihasilkan jika besar dari 0,05 maka data berdistribusi normal. Berdasarkan grafik normal p-plot dilihat dari sebaran titik yang ada, jika titik tersebar di sekitar garis diagonal dan mengikuti arah garis diagonal maka data berdistribusi normal.

Berdasarkan hasil uji kolmogorov-smirnov didapat nilai signifikansi sebesar 0,079, berarti 0,079>0,05. Kemudian berdasarkan Gambar 1 dapat dilihat bahwa titik menyebar di sekitar garis diagonal dan mengikuti arah garis diagonal. Dari hasil kedua uji normalitas tersebut, maka dapat dinyatakan bahwa data pada kajian ini berdistribusi normal.

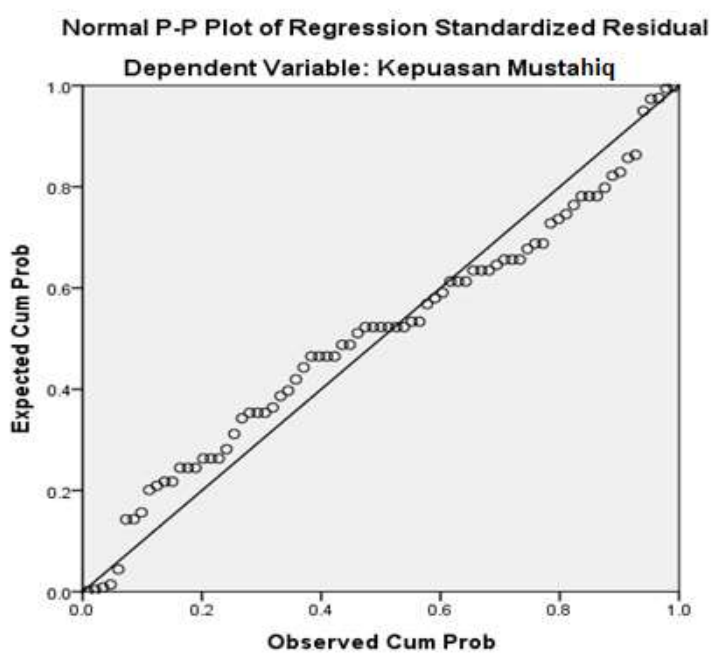

Gambar 1. Hasil Normalitas

Sumber: data primer (diolah)

\section{Regresi Linear Sederhana}

Berdasarkan Tabel 1 dapat dirumuskan persamaan regresi antara variabel kualitas pelayanan dengan kepuasan yaitu: $\mathrm{Y}=\alpha+\beta \mathrm{X} ; \mathrm{Y}=6,785+0,867 \mathrm{X}$. Persamaan tersebut 
dapat dijelaskan bahwa nilai $\alpha$ merupakan nilai konstan sebesar 6,785, artinya apabila variabel kualitas pelayanan distribusi zakat produktif bernilai nol maka didapat nilai kepuasan mustahiq sebesar 6,785. Nilai $\beta$ merupakan koefisien dari variabel kualitas pelayanan distribusi zakat produktif dengan nilai sebesar 0,867 , setiap penambahan 1 satuan variabel kualitas pelayanan distribusi zakat produktif maka nilai variabel kepuasan mustahiq akan bertambah sebesar 0,867, artinya bahwa kualitas pelayanan distribusi zakat produktif dapat mempengaruhi kepuasan mustahiq.

Tabel 1. Hasil Regresi

\begin{tabular}{lccc}
\hline \multicolumn{1}{c}{ Model } & $\boldsymbol{\alpha} / \boldsymbol{\beta}$ & $\boldsymbol{t}$ & $\boldsymbol{s i g .}$ \\
\hline (Constant) & 6,785 & 3,191 & 0,002 \\
Kualitas Pelayanan & 0,867 & 21,725 & 0,000 \\
\hline$R$ & 0,929 & & \\
$R$ Square & 0,863 & & \\
\hline \multicolumn{4}{l}{ Sumber: data primer (diolah) }
\end{tabular}

\section{Uji Hipotesis}

Berhubung variabel yang diuji hanya dua, maka pengujian dilakukan menggunakan uji t. Pengujian ini dilakukan untuk membuktikan berpengaruh atau tidaknya variabel kualitas pelayanan distribusi zakat produktif terhadap variabel kepuasan mustahiq. Dimana nilai variabel kualitas pelayanan distribusi zakat produktif diwakili oleh $t_{\text {hitung }}$ dan pembandingnya menggunakan $t_{\text {tabel}}$. Sedangkan keputusan hipotesis diambiljika nilai $t_{\text {hitung }}>t_{\text {tabel }}$ dan nilai sig. $<0,05$, maka terdapat pengaruh kualitas pelayanan distribusi zakat produktif terhadap kepuasan mustahiq dan sebaliknya tidak ada pengaruh kualitas pelayanan distribusi zakat produktif terhadap kepuasan mustahiq. Dalam menentukan nilai $\mathrm{t}_{\text {tabel }}$ diperlukan nilai $\alpha$ dan df, dimana $\alpha=0,05 / 2=0,025$; $\mathrm{df}=\mathrm{n}-\mathrm{k}=77-2=75$. Dilihat dari tabel distribusi $t$ dengan nilai $\alpha=0,025$ dan $\mathrm{df}=75$ maka didapat nilai $t_{\text {tabel }}$ sebesar 1,992. Berdasarkan Tabel 1 dapat dilihat bahwa nilai thitung sebesar 21,725 dan sig.sebesar 0,000, sehingga $t_{\text {hitung }}>t_{\text {tabel }}(21,725>1,992)$ dan sig. $<0,05(0,00<0,05)$, artinya terdapat pengaruh signifikan atau hipotesis $\mathrm{H}_{1}$ diterima.

\section{Koefisien Determinasi}

Berdasarkan Tabel 1 dapat dilihat hasil koefisien determinasi, dimana nilai $R$ sebesar 0,929 . Berhubung nilai $\mathrm{R}$ mendekati angkat 1 maka artinya terdapat hubungan yang sangat kuat antara kualitas pelayanan distribusi zakat produktif dengan kepuasan mustahiq. Kemudian nilai $R$ Square sebesar 0,863 atau $86,3 \%$, ini berarti bahwa pengaruh kualitas pelayanan distribusi zakat produktif terhadap kepuasan mustahiq yaitu sebesar $86,3 \%$.

\section{Pengaruh Kualitas Pelayanan Distribusi Zakat Produktif Terhadap Kepuasan Mustahiq}

Hasil kajian mendukung hipotesis $\mathrm{H}_{1}$, artinya kualitas pelayanan distribusi zakat produktif berpengaruh signifikan terhadap kepuasan mustahiq. Koefisien kualitas 
pelayanan distribusi zakat produktif bernilai posistif, sehingga kualitas pelayanan distribusi zakat produktif berpengaruh positif dan signifikan terhadap kepuasan mustahiq. Hal tersebut menandakan bahwa jika kualitas pelayanan distribusi zakat produktif baik maka akan memberikan kepuasan bagi mustahiq. Sebaliknya jika kualitas pelayanan distribusi zakat produktif buruk maka akan menghasilkan ketidakpuasan bagi mustahiq.

Kualitas pelayanan distribusi zakat produktif memegang peran penting dalam meningkatkan kepuasan mustahiq. Hal ini dibuktikan oleh petugas distribusi zakat produktif BAZNAS Kabupaten Bengkalis di lapangan melalui kecermatan petugas dalam melayani mustahiq, adanya komunikasi yang baik dengan musqtahiq, memberikan kepastian pelayanan kepada mustahiq, memberikan kenyamanan dalam pelayanan kepada mustahiq, memberikan kemudahan dalam proses pelayanan, terdapatnya kedisplinan petugas dalam pelayanan, petugas melayani mustahiq dengan ramah dan sopan, petugas menghargai dan tidak membeda-bedakan mustahiq, petugas melakukan pelayanan dengan cepat dan merespon keluhan dari mustahiq. Semua hal yang dilakukan petugas distribusi zakat produktif dilapangan,sudah mewakili dimensi kualitas pelayanan yaitu reliability, assurance, tangible, empathy dan responsiviness. Mustahiq BAZNAS Kabupaten Bengkalis sudah puas atas pelayanan yang diberikan oleh petugas. BAZNAS Kabupaten Bengkalis sudah menyalurkan zakat produktif secara efektif dan tepat pada sasaran. Dana zakat produktif yang disalurkan dimanfaatkan mustahiq untuk kebutuhan usaha dalam meningkatkan perekonomian keluarga.

Hasil kajian ini sejalan dengan temuan dari kajian-kajian yang dilakukan oleh (Afthanorhan et al., 2019; Alvianna, 2017; Biswas \& Roy, 2020; Budiarti, 2011; Dewi et al., 2021; Farida, 2017; Hidayah et al., 2020; Hilal \& Djatola, 2018; Kang, 2020; Kumar et al., 2020; Lubis et al., 2021; Maharsi et al., 2021; Mubarok, 2016; Mutmainnah, 2018; Ndayisenga \& Tomoliyus, 2019; Pawirosumarto, 2016; Roh \& Choi, 2019; Setiawan, 2016; Shartykarini et al., 2016; Stephen et al., 2019; Supriyanto et al., 2021; Xiao et al., 2020; Yudhistira, 2019) yang menyatakan bahwa kualitas pelayanan berpengaruh signifikan terhadap kepuasan. Namun hasil kajian ini tidak selajan dengan temuan dari (Al Idrus et al., 2021) yang menyatakan bahwa kualitas pelayanan berpengaruh negatif dan siginifikan terhadap kepuasan.

\section{E. KESIMPULAN}

Ternyata kualitas pelayanan distribusi zakat produktif memiliki urgensi dalam menciptakan kepuasan kepada mustahiq BAZNAS Kabupaten Bengkalis. Pendistribusian zakat produktif BAZNAS Kabupaten Bengkalis sudah mengikuti ketentuan dalam Undang-Undang Nomor 23 Tahun 2011. Kajian ini mengungkap bahwa kualitas pelayanan distribusi zakat produktif sangat kuat hubungannya dengan kepuasan mustahiq. Terbukti bahwa kualitas pelayanan distribusi zakat produktif berpengaruh positif dan signifikan terhadap kepuasan mustahiq di BAZNAS Kabupaten Bengkalis dengan besar pengaruh 86,3\%.

Kajian ini menambah bukti baru dari kajian yang telah ada pada sektor berbeda yaitu sektor sosial keagamaan tepatnya pengelolaan zakat produktif. Kajian ini memberikan kontribusi 
kepada BAZNAS Kabupaten Bengkalis dalam meningkatkan kualitas pelayanan dan kepuasan mustahiq zakat produktif. Kajian ini memiliki keterbatasan dalam ruang lingkup, waktu dan pengambilan sampel. Ruang lingkup kajian hanya melihat kepuasan dan kualitas pelayanan. Kemudian kondisi pandemi covid-19 membatasi waktu dan pengambilan sampel, sehingga sebaran sampel belum sepenuhnya menyentuh semua wilayah Kabupaten Bengkalis.

Harapan kedepan, supaya BAZNAS kabupaten Bengkalis mempertahankan dan meningkatkan pengelolaan zakat produktif. Kemudian diharapkan pada BAZNAS kabupaten Bengkalis agar dapat meningkatkan jumlah dana zakat produktif, sehingga berimbang dengan alokasi dana zakat konsumtif. Kajian selanjutnya diharapkan dapat menambah jumlah sampel dengan pengambilan sampel merata di seluruh wilayah kabupaten Bengkalis. Diharapkan kajian selanjutnya juga dapat menambah variabel-variabel yang kait terkait dengan kepuasan seperti persepsi, pengatahuan, kepercayaandan sebagainya.

\section{DAFTAR PUSTAKA}

Afthanorhan, A., Foziah, H., Rusli, R., \& Khalid, S. (2019). The effect of service quality on customer satisfaction in three campuses of UniSZA. International Journal of Innovation, Creativity and Change, 7(10), 42-56. Retrieved from https://www.ijicc.net/images/vol7iss10/71004_Afthanorhan_2019_E_R.pdf

Akbar, F. H., Ulfah, U., \& Maretta, Y. A. (2020). The effect of health services quality on satisfaction and loyalty in West Sulawesi Province, Indonesia. Open Access Macedonian Journal of Medical Sciences, 8(D), 150-157. https://doi.org/10.3889/oamjms.2020.4290

Al Idrus, S., Abdussakir, A., Djakfar, M., \& Al Idrus, S. (2021). The Effect of Product Knowledge and Service Quality on Customer Satisfaction. Journal of Asian Finance,

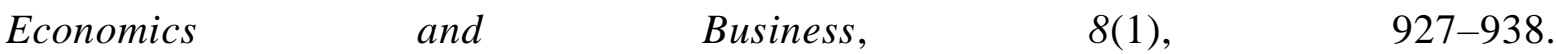
https://doi.org/10.13106/jafeb.2021.vol8.no1.927

Alam, M. J. (2021). Effects of service quality on satisfaction in Eastern University Library, Bangladesh. IFLA Journal, 47(2), 209-222. https://doi.org/10.1177/0340035220959099 Alamgir Hossain, M., Yesmin, M. N., Jahan, N., \& Kim, M. (2021). Effects of service justice, quality, social influence and corporate image on service satisfaction and customer loyalty: Moderating effect of bank ownership. Sustainability (Switzerland), 13(13), 113. https://doi.org/10.3390/su13137404

Alvianna, S. (2017). Analisis Pengaruh Harga, Produk, Dan Kualitas Layanan Terhadap Kepuasan Wisatawan Di Taman Wisata Air Wendit Kabupaten Malang. Jurnal Pariwisata Pesona, 2(1), 1-12. https://doi.org/10.26905/jpp.v2i1.1263

Anwar, A. T. (2018). Zakat Produktif Untuk Pemberdayaan Ekonomi Umat. ZISWAF: Jurnal Zakat Dan Wakaf, 5(1), 41-62. https://doi.org/10.21043/ziswaf.v5i1.3508

Aslam, W., Tariq, A., \& Arif, I. (2019). The Effect of ATM Service Quality on Customer Satisfaction and Customer Loyalty: An Empirical Analysis. Global Business Review, 20(5), 1155-1178. https://doi.org/10.1177/0972150919846965

e1-Jizya: Jurnal Ekonomi Islam, Vol. 9, No. 2, Juli-Desember 2021

122 I http://ejourna1.iainpurwokerto.ac.id/index.php/eljizya 
Atabik, A. (2015). Manajemen Pengelolaan Zakat Yang Efektif Di Era Kontemporer. Ziswaf: Jurnal Zakat Dan Wakaf, 2(1), 40-62. Retrieved from https://journal.iainkudus.ac.id/index.php/Ziswaf/article/view/1535

Balinado, J. R., Prasetyo, Y. T., Young, M. N., Persada, S. F., Miraja, B. A., \& Redi, A. A. N. P. (2021). The effect of service quality on customer satisfaction in an automotive aftersales service. Journal of Open Innovation: Technology, Market, and Complexity, 7(2), 1-12. https://doi.org/10.3390/joitmc7020116

Biswas, B., \& Roy, S. K. (2020). Service quality, satisfaction and intention to use Union Digital Center in Bangladesh: The moderating effect of citizen participation. PLoS ONE, 15(12), 1-14. https://doi.org/10.1371/journal.pone.0244609

Budiarti, A. (2011). Pengaruh Kualitas Layanan Dan Penanganan Keluhan Terhadap Kepuasan Dan Loyalitas Nasabah Bank Umum Syariah Di Surabaya. Ekuitas (Jurnal Ekonomi Dan Keuangan), 15(2), 210-231. https://doi.org/10.24034/j25485024.y2011.v15.i2.229

Dewi, D., Hajadi, F., Handranata, Y. W., \& Herlina, M. G. (2021). The effect of service quality and customer satisfaction toward customer loyalty in service industry. Uncertain Supply Chain Management, 9(3), 631-636. https://doi.org/10.5267/j.uscm.2021.5.007

Edinger, S. K., \& Edinger, M. J. (2018). Improving Teacher Job Satisfaction: The Roles of Social Capital, Teacher Efficacy, and Support. The Journal of Psychology, 152(8), 573593. https://doi.org/10.1080/00223980.2018.1489364

Ernawaty, E., Supriyanto, S., Krisbianto, K., \& Visianti, V. (2020). The effect of hospital service quality on inpatient satisfaction in piru hospital. Journal of Health and Translational Medicine, 23(1), 155-162. Retrieved from https://jummec.um.edu.my/article/view/25843

Farida, T. (2017). Pengaruh Customer Relationship Management Dan Kualitas Layanan Terhadap Kepuasan Dan Loyalitas Investor PT Danareksa Medan. Jurnal Ilmiah Manajemen Dan Bisnis, 17(1), 101-123. Retrieved from http://jurnal.umsu.ac.id/index.php/mbisnis/article/view/981

Farooq, M. S., Salam, M., Fayolle, A., Jaafar, N., \& Ayupp, K. (2018). Impact of service quality on customer satisfaction in Malaysia airlines: A PLS-SEM approach. Journal of Air Transport Management, 67, 169-180. https://doi.org/10.1016/j.jairtraman.2017.12.008

Fauzi, A. A., \& Suryani, T. (2019). Measuring the effects of service quality by using CARTER model towards customer satisfaction, trust and loyalty in Indonesian Islamic banking. Journal of Islamic Marketing, 10(1), 269-289. https://doi.org/10.1108/JIMA-04-20170048

Heizmann, B., \& Böhnke, P. (2019). Immigrant life satisfaction in Europe: the role of social and symbolic boundaries. Journal of Ethnic and Migration Studies, 45(7), 1027-1050. https://doi.org/10.1080/1369183X.2018.1438252

Hendarsyah, D. (2013). Pemanfaatan Zakat Online Baznas Bagi Muzaki. IQTISHADUNA: Jurnal Ilmiah Ekonomi Kita, 2(2), 485-512. https://doi.org/10.46367/iqtishaduna.v2i2.32

Hidayah, R. T., Tauwli, M. D. F., \& Saefudin, N. (2020). The effects of mobile service quality 
and E-recovery service quality on e-satisfaction in bukalapak application users. International Journal of Psychosocial Rehabilitation, 24(2), 3087-3092. https://doi.org/10.37200/IJPR/V24I2/PR200613

Hilal, N., \& Djatola, H. R. (2018). Pengaruh Kualitas Layanan Terhadap Kepuasan Nasabah dan Gethok Tular pada Bank Syariah di Kota Palu. J-MKLI (Jurnal Manajemen Dan Kearifan Lokal Indonesia), 2(1), 23-33. https://doi.org/10.26805/jmkli.v2i1.14

Ishak, K. (2012). Zakat Dalam Sistem Ekonomi Islam Sebuah Alternatif Dalam Peningkatan Kesejahteraan. IQTISHADUNA: Jurnal Ilmiah Ekonomi Kita, 1(1), 166-181. Retrieved from http://ejournal.stiesyariahbengkalis.ac.id/index.php/iqtishaduna/article/view/10

Islam, R., Ahmed, S., Rahman, M., \& Asheq, A. Al. (2020). Determinants of service quality and its effect on customer satisfaction and loyalty: an empirical study of private banking sector. TQM Journal. https://doi.org/10.1108/TQM-05-2020-0119

Kang, M.-J. (2020). A study on the effect of service quality, consumer empathy and shopping value on curation commerce satisfaction. Journal of Distribution Science, 18(6), 5-14. https://doi.org/10.15722/jds.18.6.20206.5

Kumar, D., Govindarajo, N. S., \& Khen, M. H. S. (2020). Effect of service quality on visitor satisfaction, destination image and destination loyalty - practical, theoretical and policy implications to avitourism. International Journal of Culture, Tourism, and Hospitality Research, 14(1), 83-101. https://doi.org/10.1108/IJCTHR-04-2019-0066

Lubis, A., Dalimunthe, R., Absah, Y., \& Fawzeea, B. K. (2021). The Effect of Corporate Communication and Service Quality on Customer Loyalty and Satisfaction in Sharia Banking. Journal of Asian Finance, Economics and Business, 8(3), 1267-1274. https://doi.org/10.13106/jafeb.2021.vol8.no3.1267

Maharsi, A. R., Njotoprajitno, R. S., Hadianto, B., \& Wiraatmaja, J. (2021). The Effect of Service Quality and Customer Satisfaction on Purchasing Intention: A Case Study in Indonesia. Journal of Asian Finance, Economics and Business, 8(4), 475-482. https://doi.org/10.13106/jafeb.2021.vol8.no4.0475

Mubarok, N. (2016). Pengaruh Dimensi Kualitas Layanan Kredit terhadap Kepuasan Debitur Usaha Mikro dan Kecil (UMK) pada Bank Tabungan Pensiunan Nasional. I-FINANCE: A Research Journal On Islamic Finance, 2(1), 86-98. Retrieved from http://jurnal.radenfatah.ac.id/index.php/I-Finance/article/view/1011

Mushaf. (2021). Al-Quran Online. Retrieved August 29, 2021, from mushaf.id website: https://www.mushaf.id/surat/at-taubah/

Mutmainnah, M. (2018). Pengaruh Kualitas Layanan Dan Citra Perusahaan Terhadap Kepuasan Dan Loyalitas Nasabah. Jurnal Manajemen Dan Pemasaran Jasa, 10(2), 201-216. https://doi.org/10.25105/jmpj.v10i2.2344

Nasrul, N. (2021). The effect of service quality, customer learning on corporate image, satisfaction, commitment, loyality, and customer savings interests and decisions: A study at government banks in Southeast Sulawesi. International Journal of Electronic Government Research, 17(2), 43-61. https://doi.org/10.4018/IJEGR.2021040103

Ndayisenga, J., \& Tomoliyus, T. (2019). Effect of service quality and rates on satisfaction and 
loyalty of customer behavior at fitness. International Journal of Human Movement and Sports Sciences, 7(2), 25-32. https://doi.org/10.13189/saj.2019.070202

Nunkoo, R., Teeroovengadum, V., Ringle, C. M., \& Sunnassee, V. (2020). Service quality and customer satisfaction: The moderating effects of hotel star rating. International Journal of Hospitality Management, 91. https://doi.org/10.1016/j.ijhm.2019.102414

Owoyemi, M. Y. (2020). Zakat management: The crisis of confidence in zakat agencies and the legality of giving zakat directly to the poor. Journal of Islamic Accounting and Business Research, 11(2), 498-510. https://doi.org/10.1108/JIABR-07-2017-0097

Pandey, R., Ganatra, V., Jamnik, S., Goel, P., Goyal, P., Xuan, C. L., ... Zen, L. J. (2021). An Empirical Study on Customer Satisfaction, Perception, and Brand Image in Starbucks Coffee in India, Asia. International Journal of Tourism and Hospitality in Asia Pasific, 4(1), 53-63. https://doi.org/10.32535/ijthap.v4i1.1021

Pawirosumarto, S. (2016). Pengaruh kualitas sistem, kualitas informasi, dan kualitas layanan terhadap kepuasan pengguna sistem e-learning. MIX: Jurnal Ilmiah Manajemen, 6(3), 416-433.

Retrieved

from

https://journal.mercubuana.ac.id/index.php/Jurnal_Mix/article/view/1280

Pradeep, S., Vadakepat, V., \& Rajasenan, D. (2020). The effect of service quality on customer satisfaction in fitness firms. Management Science Letters, 10(9), 2011-2020. https://doi.org/10.5267/j.ms1.2020.2.011

Rahaman, M. A., Ali, M. J., Kejing, Z., Taru, R. D., \& Mamoon, Z. R. (2020). Investigating the Effect of Service Quality on Bank Customers' Satisfaction in Bangladesh. Journal of Asian Finance, Economics and Business, 7(10), 823-829. https://doi.org/10.13106/jafeb.2020.vol7.n10.823

Roh, T. H., \& Choi, H. Y. (2019). Effect of service quality of domestic air ticket payment application on satisfaction and purchasing intention. Asia Life Sciences, (1), 539-549. Retrieved from https://www.scopus.com/inward/record.uri?eid=2-s2.085062658677\&partnerID=40\&md5=f2029cecb8ac32ffe14859f87542653b

Safradji, S. (2018). Zakat Konsumtif Dan Zakat Produktif. Tafhim Al-'Ilmi: Jurnal Pendidikan Dan Pemikiran Islam, 10(1), 59-66. https://doi.org/10.37459/tafhim.v10i1.3246

Saputra, H. (2020). Zakat Sebagai Sarana Bantuan Bagi Masyarakat Berdampak Covid-19. AlIjtima'i: International Journal of Government and Social Science, 5(2), 161-175. https://doi.org/10.22373/jai.v5i2.549

Setiawan, H. (2016). Pengaruh Kualitas Layanan, Persepsi Nilai dan Kepercayaan terhadap Kepuasan dan Loyalitas Pengguna Layanan Mobile Banking. Jurnal Keuangan Dan Perbankan, 20(3), 518-528. https://doi.org/10.26905/jkdp.v20i3.269

Shartykarini, S., Firdaus, R., \& Rusniati, R. (2016). Pengaruh Harga, Kualitas Produk dan Kualitas Layanan Terhadap Kepuasan Pelanggan dalam Membentuk Loyalitas Pelanggan (Studi Pengunjung Cafe di Banjarbaru). JWM (Jurnal Wawasan Manajemen), 4(1), 39-52. Retrieved from https://jwm.ulm.ac.id/id/index.php/jwm/article/view/76

Stephen, T. B., Abu, N. Z., Loy, C. K., \& Belkhamza, Z. (2019). The effect of administrative service quality and lecturer's teaching quality on students' satisfaction in higher learning 
institutions in Kota Kinabalu, Sabah. International Journal of Innovation, Creativity and Change, 6(4), 260-376. Retrieved from https://www.ijicc.net/images/Vol6Iss4/6421_Stephen_2019_TD_R.pdf

Supriyanto, A., Wiyono, B. B., \& Burhanuddin, B. (2021). Effects of service quality and customer satisfaction on loyalty of bank customers. Cogent Business and Management, 8(1), 1-17. https://doi.org/10.1080/23311975.2021.1937847

Tsurumi, T., \& Managi, S. (2020). Health-related and non-health-related effects of PM2.5 on life satisfaction: Evidence from India, China and Japan. Economic Analysis and Policy, 67, 114-123. https://doi.org/10.1016/j.eap.2020.06.002

Wiyanto, W. (2016). Analisis Pengaruh Kualitas Pelayanan terhadap Kepuasan Tinggi dan Rendah Nasabah di Bank Syari'ah Mandiri Cabang Salatiga. Muqtasid: Jurnal Ekonomi Dan Perbankan Syariah, 7(2), 117-135. https://doi.org/10.18326/muqtasid.v7i2.117135

Xiao, Y., Ren, X., Zhang, P., \& Ketlhoafetse, A. (2020). The effect of service quality on foreign participants' satisfaction and behavioral intention with the 2016 Shanghai International Marathon. International Journal of Sports Marketing and Sponsorship, 21(1), 91-105. https://doi.org/10.1108/IJSMS-04-2019-0037

Yudhistira, P. G. A. (2019). The effect of service quality on online transportation customer satisfaction in denpasar city. International Journal of Recent Technology and Engineering (IJRTE), $8(2$ Special Issue), 121-125. Retrieved from https://www.ijrte.org/wp-content/uploads/papers/v8i2S/B10180782S19.pdf 